\title{
Transport characteristics and morphology of the colon and coprodeum in two wild birds of different habitats, the rock ptarmigan (Lagopus mutus) and the common murre and (Uria aalge).
}

Sighvatur S. Árnason ${ }^{1}$, Vibeke S. Elbrønd ${ }^{2}$, Gary Laverty ${ }^{3}$

${ }^{1}$ Department of Physiology, University of Iceland, Reykjavík, Iceland, ${ }^{2}$ Department of

Veterinary Clinical and Animal Sciences, University of Copenhagen, Copenhagen, Denmark;

${ }^{3}$ Department of Biological Sciences, University of Delaware, Newark, USA

Short title:

Transport and morphology of lower intestine in Lagopus mutus and Uria aalge

Corresponding author:

Gary Laverty, Department of Biological Sciences, 244 Wolf Hall, University of Delaware, Newark, DE 19716 EM: Laverty@udel.edu 3028318180

Footnotes:

SGLT, sodium-glucose luminal cotransporter

$\mathrm{ENaC}$, epithelial $\mathrm{Na}^{+}$channel

$\mathrm{I}_{\mathrm{sc}}$, short-circuit current 


\begin{abstract}
Changes in dietary salt intake in the domestic fowl cause alterations in the epithelial transport patterns and morphology of the lower intestine (colon and coprodeum). This study was designed to investigate lower intestinal morphology and transport activity in two wild bird species with natural diets containing either low or high salt. Rock ptarmigan (Lagopus mutus, $\mathrm{n}=9$ ) and common murres (Uria aalge, $\mathrm{n}=13$ ) were caught in south-west Iceland, and lower intestinal tissues were sampled for histology and electrophysiology. The ptarmigan exists on a high fiber, low salt diet, while the murre lives on a diet of high protein and relatively high salt. The ptarmigan colon and coprodeum had villi/folds and crypts and the columnar epithelium contained 3 cell types, absorptive epithelial cells, mitochondria-rich cells and goblet cells. The colon had a significant amiloride-inhibitable $\mathrm{I}_{\mathrm{sc}}, 5-15 \mu \mathrm{A} / \mathrm{cm}^{2}$, with no glucose-stimulated $\mathrm{I}_{\mathrm{sc}}$, and no significant phloridzin inhibition. The coprodeum also had high amiloride-inhibitable $\mathrm{I}_{\mathrm{sc}}$. This lower intestinal transport pattern corresponded to that of chickens following long-term adaptation to low-salt diets. However, the ptarmigan colon also had a significant lysine/leucine-stimulated $\mathrm{I}_{\mathrm{sc}}$ of $3 \pm 1.0 \mu \mathrm{A} / \mathrm{cm}^{2}$, reminescent of high-salt chicken colon. Marine Uria aalge live constantly on high-salt diet. The cellular structure of their short colon was similar to that of ptarmigans, although it had no villi, only crypts, and it demonstrated a significant lysine/leucine-stimulated $\mathrm{I}_{\mathrm{sc}}\left(11 \pm 3.5 \mu \mathrm{A} / \mathrm{cm}^{2}\right)$ with no amiloride-inhibitable $\mathrm{I}_{\mathrm{sc}}$. This pattern is similar to the high-salt adapted chicken colon, but differed in having no $\mathrm{Na}^{+}$-glucose cotransport, which was demonstrated by the absence of glucose-stimulated $\mathrm{I}_{\mathrm{sc}}$ and phloridzin effect. The murre coprodeum was inert to all substances and showed high resistance $\left(1000 \mathrm{ohm} \mathrm{cm}^{2}\right)$, with a markedly different structure of a multilayered squamous epithelium. Despite some variations possibly associated with dietary protein intake, we conclude that natural high and low salt diets in different avian
\end{abstract}


species are associated with different epithelial transport patterns in the lower intestine, providing for post-renal adjustments in ion and water excretion.

Keywords

Lagopus mutus; Uria aalge; high/low salt diets; colon; coprodeum; epithelial morphology; amiloride; $\mathrm{Na}^{+} /$glucose cotransport; $\mathrm{Na}^{+}$/amino acid cotransport; SGLT, phloridzin 


\section{Introduction}

The avian urinary system differs significantly from that of mammals in that birds generally have a more limited renal concentrating ability, they excrete insoluble uric acid as a nitrogenous waste product, and they lack a urinary bladder (Braun, 2003, Laverty and Skadhauge, 1999, Laverty et al, 2006). In a number of species, ureteral urine entering the coprodeum is known to reflux into the large intestine due to antiperistaltic contractions (Braun, 2003). Transport activity in this segment may then modify the urine composition with extensive absorption of ions, organic solutes and water (Laverty and Skadhauge, 1999, Laverty et al, 2006).

The lower intestine (colon and coprodeum) of the domestic fowl (Gallus gallus domesticus) has been extensively studied both morphologically and physiologically, as well as with respect to changes that occur with dietary salt loads. The colon of the domestic fowl has an unusual transport system, in which sodium-linked cotransporters for hexoses and amino acids are expressed on high salt diets, but are suppressed with low salt diets or aldosterone administration (Árnason and Skadhauge 1991; Clauss et al, 1991; Lind et al, 1980; Laverty et al. 2001; 2006). With high levels of circulating aldosterone (ie, low salt diets) there is, instead, a high level of activity of electrogenic epithelial sodium channels or ENaCs. Colonic organic substrate transport has also been reported for a few other avian species (Goldstein, 1993; Laverty, 1997; Skadhauge and Dawson, 1980; Skadhauge et al, 1984). There is no transport in the coprodeum of chickens on high salt diet, but with low salt intake there is a high level of ENaC activity as in the colon (Árnason and Skadhauge, 1991; Chosniak et al, 1977; Clauss et al, 1988). This switch in the pattern of transporter/channel activity is both reversible and nearly complete when birds are fully adapted to high or low salt diets (Árnason and Skadhauge 1991). Changes in dietary $\mathrm{NaCl}$ intake and plasma aldosterone also markedly affect the morphology of the coprodeum of chickens, with low 
salt diets causing induction of a brush border and changes in the relative proportions of cell types, with an increase in mitochondria-rich cells (MR) (Elbrønd et al. 1991, 1998, 1999, Mayhew et al. 1992).

Although many of the details of epithelial transport in the avian colon are known, the physiological role or roles of hexose and amino acid cotransporter expression are still not clear. Lower intestinal substrate transport may play a role in the absorption of nutrients that are not absorbed in the small intestine, or that reflux into the lower intestine from the urine (Laverty and Skadhauge, 1999; Laverty et al, 2006). Alternatively, it has been hypothesized that the function of these transport systems is to counteract osmotic outflow from extracellular fluid into the lumen, especially in birds on high salt diets (Árnason and Skadhauge, 1991; Laverty and Skadhauge, 1999). Earlier studies had shown that on high salt diets there is an inflow of hypertonic fluid into the colon from both the small intestine and the kidney (Skadhauge, 1968; Thomas 1982). Thus, solute absorption and potential solute-linked water absorption in the colon may be important in offsetting the potential water loss into the lumen. Under low salt conditions, on the other hand, the high level of ENaC activity likely facilitates salt conservation.

While the domestic fowl is a useful experimental model, it is of interest to continue to gather data on other species with diverse dietary and osmoregulatory natural histories. The osmotic challenges of the common murre (guillemot), Uria aalge, and the rock ptarmigan, Lagopus mutus are representative of species at opposite ends of the dietary salt spectrum. These two holarctic species, both common in Iceland, have highly contrasting diets.

The murre lives constantly at sea except for the summer reproduction period, when it dwells on cliffs and rocks by the seashore and on rocky islands (Gaston and Jones, 1998). Murres feed on fish and marine invertebrates and would be expected to be fully adapted to a relatively high salt and high protein intake (Bradstreet and Brown, 1985; Lilliendahl and 
Solmundsson, 1997), but with low free water intake. The ingested daily salt load needs to be excreted efficiently. During summer this salt load for the most part comes in the form of caplin and sandeel, and some krill (Lillendahl and Solmundsson, 1997), as well as some seawater ingested with the food. Like other seabirds, they presumably also drink seawater specifically (Schmidt-Nielsen, 1997; Skadhauge, 1981). Seabirds are known to gain free water by excreting salt through special nasal salt glands (Holmes and Phillips, 1985; Schmidt-Nielsen, 1997). Their kidneys have moderate concentrating abilities and urine is refluxed into the lower intestine where some of the salt and water is reabsorbed (Goldstein and Skadhauge, 2000; Skadhauge, 1981; Skadhauge et al, 1984). Schmidt-Nielsen et al (1963) put forth the hypothesis that the absorption of salt and water from the urine in the intestine and subsequent salt excretion by the salt glands helps in gaining free water. The major osmotic challenges for this species is clearly water conservation and salt excretion.

In contrast the rock ptarmigan has relatively little salt in its diet and usually there is no shortage of fresh water in the areas it populates in Iceland. This species lives in sparsely vegetated highlands and lava fields in Iceland and subsists on a high fiber, high carbohydrate diet of leaves, buds, twigs and berries (Johnsgard, 1983). These birds have low salt and low protein intake, but high free-water intake. Thus, the primary osmotic challenge for this species is salt conservation. As with other grouse and teraonids, the high fiber diet is correlated with a relatively large lower intestine, both the colon and especially the ceca, which are thought to function in the fermentative breakdown of plant materials (Gasaway, 1976; Moss, 1989).

This study was designed to study the morphology and transport properties of the lower intestine of these two species on natual diets, and to compare these properties with those of the domestic fowl on high and low salt diets. Our results demonstrate that the murre and 
ptarmigan colonic epithelia do in some ways but not in others exhibit morphology and transport patterns similar, respectively, to those of high and low salt-adapted domestic fowl. 


\section{Materials and Methods}

\section{Animals and tissue collection}

Nine Lagopus mutus (mean body weight $504 \pm 5 \mathrm{~g}$ ) and 13 Uria aalge (mean body weight $825 \pm 17 \mathrm{~g}$ ) were used in this study. The ptarmigans were obtained in the wilderness east of Reykjavík, one on any given day, by a licensed hunter (see Acknowlegements). Tissues from the lower intestine were removed within $10 \mathrm{~min}$ of sacrifice and stored in icecold, pre-oxygenated buffer (see below for composition). Transport back to the laboratory generally took about $30 \mathrm{~min}$. The total time from sacrifice to mounting in Ussing chambers averaged 2-3 hours, with constant oxygenation during most of this time. Because of its relatively long length $(7-8 \mathrm{~cm})$, the Lagopus colon was arbitrarily divided into three axial regions, proximal (adjacent to the ileal-cecal junction), mid and distal (closest to the coprodeum). Samples for histology and electron microscopy were taken from the mid section only. The coprodeum was $2-3 \mathrm{~cm}$ long in this species.

The Uria aalge birds were captured by licensed hunters from the cliffs of Krísuvíkurbjarg on the western south coast of Iceland and transported back to the department in Reykjavík, where they were housed in cages at $5{ }^{\circ} \mathrm{C}$ for either 1 or 2 nights. Birds were sacrificed by decapitation and tissues were removed immediately. Because of the short length of colon $(0.8-1 \mathrm{~cm})$, only one sample of colon could be used from each animal. The coprodeum was around $2 \mathrm{~cm}$ in length. Colon and coprodeum from five birds were used for electrophysiology, and the rest for either histology or immunoblotting.

\section{Histology and Morphology}

For both light microscopy (LM) and transmission electron microscopy (TEM), tissues were pinned to flat pieces of polystyrene and immersion fixed in $3 \%$ glutaraldehyde in, 
respectively, $0.1 \mathrm{M}$ cacodylate or phosphate buffer, $\mathrm{pH} 7.2$, followed by postfixation in $1 \%$ osmium tetraoxide. Tissues were dehydrated, then embedded in epon and cut into $1 \mu \mathrm{m}$ thick sections and studied in a Leica DMR microscope. These sections were stained with toluidine blue to highlight the different cell types present. For TEM, 40 to $70 \mathrm{~nm}$ ultrathin sections were cut, stained with uranyl-acetate and Reynolds lead-citrate and examined with a Phillips CM 100 electron microscope. For scanning electron microscopy (SEM) the tissue was fixed in 3\% glutaraldehyde in cacodylate/phosphate buffer, the samples were dehydrated in a graded acetone series and critical-point dried. Samples were coated with a $20 \mathrm{~nm}$ gold layer and examined in a JEOL 840A scanning electron microscope (Elbrønd et al. 1998; 1999).

In the domestic fowl the major cell types of the lower intestinal epithelium are the absorptive epithelial cells (AEC), goblet cells (GC) and mitochondria-rich cells (MR). The relative proportions of these same three cell types were estimated in the colon and coprodeum of Lagopus mutus and in the colon of Uria aalge (the coprodeum of Uria aalge had a distinctly different epithelium as described below, and was not examined for cell types). Toluidine blue-stained LM sections were examined at 400x magnification. For each species, multiple random fields of view were taken from tissue blocks from 3 or 4 individual birds. For Lagopus mutus, cells were counted along the margins of a colonic villus or a coprodeal fold, following the crypt-villus axis. For Uria aalge colon cells were counted along the intercryptal epithelium (the surface epithelium between the crypts) and the epithelium in the upper part of the crypts. For each tissue, between 200 and 800 total cells were counted to obtain the cell type estimates.

\section{Electrophysiology}

These techniques were as previously described (Árnason and Skadhauge 1991) and are designed to measure the changes in transepithelial short circuit current $\left(\mathrm{I}_{\mathrm{SC}}\right)$ due to sodiumcoupled cotransporters (sodium-glucose and sodium-amino acid), to amiloride-sensitive, 
electrogenic sodium channels (ENaCs), or to cAMP-activated chloride secretion. Briefly, tissues (colon and coprodeum) were washed and pre-equilibrated in ice-cold, pre-oxygenated transport buffer containing (in $\mathrm{mM}$ ): $140 \mathrm{Na}^{+}, 8 \mathrm{~K}^{+}, 2.6 \mathrm{Ca}^{++}, 1.0 \mathrm{Mg}^{++}, 139 \mathrm{Cl}^{-}, 8 \mathrm{PO}_{4}{ }^{3-}$, and 1.0 $\mathrm{SO}_{4}{ }^{2-}, \mathrm{pH}$ 7.3. Segments were then mounted, with the muscle layer (tunica) intact, into Ussing chambers with an aperture area of $0.62 \mathrm{~cm}^{2}$. The same transport buffer was continuously aerated and circulated from reservoirs on each side with $100 \% \mathrm{O}_{2}$. The serosal solution additionally contained $20 \mathrm{mM}$ glucose, whereas the mucosal side was initially glucose free.

Agar-Ringer bridges were used to measure the transepithelial potential (PD) with connection to paired calomel reference electrodes. Current electrodes were $\mathrm{Ag} / \mathrm{AgCl}$ wires inserted into the chambers. The tissues were electrically clamped to zero PD with automatic voltage clamps, pre-adjusted for fluid resistance compensation, thus allowing measurement of the $\mathrm{I}_{\mathrm{sc}}$. There was a $1 \mathrm{~min}$ break in the clamp circuit every 3 min to record open-circuit PD. Transepithelial resistance (TER), in units of $\mathrm{ohm} \mathrm{cm}^{2}$, was thus calculated from Ohm's Law. By convention, PD was recorded as mucosal side relative to serosal side, and a positive $\mathrm{I}_{\mathrm{sc}}$ indicates a positive mucosal to serosal current flow, identified as sodium flux in the lower intestine of domestic fowl (Chosniak et al, 1977; Lind et al, 1980; Skadhauge, 1981).

Under the conditions described above, tissues were allowed to stabilize for approximately $60 \mathrm{~min}$ before beginning experimental manipulations. At this time glucose was added to the mucosal side reservoir, to a final concentration of $20 \mathrm{mM}$, in order to assay for functional expression of sodium-glucose cotransport (SGLT) activity. The resulting change in $\mathrm{I}_{\mathrm{sc}}$ was monitored for $20 \mathrm{~min}$. Following glucose addition, a mixture of the amino acids leucine and lysine ( $4 \mathrm{mM}$ each) was added to both sides, followed, in turn, by the SGLT glucose transport inhibitor phloridzin ( $100 \mu \mathrm{M}$ both sides), by amiloride, a blocker of 
electrodiffusive epithelial sodium channels ("ENaCs") (100 $\mu \mathrm{M}$ mucosal side), and finally by theophylline, an inhibitor of phosphodiesterase (1.4 mM both sides). Twenty to thirty min stabilization periods were allowed between each addition.

Currents in these tissues were generally stable. Nevertheless, we routinely calculated changes in $\mathrm{I}_{\mathrm{sc}}$ by establishing a mathematical trend for the previous condition and extrapolating values for the last 15 min of the previous condition for an additional 25 min into the new treatment period. A delta $\mathrm{I}_{\mathrm{sc}}$ was then calculated as the difference between this extrapolated pretreatment level and a stabilized posttreatment value, both measured 15-20 min after the addition (Árnason and Skadhauge 1991).

\section{Data Analysis and Statistics.}

All data are expressed as means \pm SEM. Differences between initial values were tested by ANOVA and Student's t-tests. Changes in $\mathrm{I}_{\mathrm{sc}}$ with each treatment are calculated as delta values from the previous trendline, as described above. These delta values were then analyzed by testing for significance from zero ("zero test"). 


\section{Results}

\section{Histology and Morphology.}

In general terms the epithelium in colon and coprodeum of Lagopus mutus and in colon of Uria aalge demonstrated typical morphological features associated with active transport. The epithelium was a monolayer of polarized columnar cells with a brush-border outlining the surface towards the lumen (Figs. 1c, e, f, 2c, e, f and 3c, e, f), infoldings of the lateral membranes and tight junctions sealing the intercellular space apically (Figs. 1f, 2f, 3f). Additionally this was supported with the presence of cyto-organelles such as RER, transport vesicles and mitochondria in frequent amount/number. Light microscopy (LM) and electron microscopy (TEM and SEM) (see Figs. 1c, e, f, 2c, e, f and 3c, e, f) showed the presence of three main cell types in the monolayered epithelium: Absorptive intestinal epithelial cells (AEC), mitochondria-rich cells (MR), and goblet cells (GC). Migrating lymphocytes were present in the intercellular space in both species. In contrast to this the coprodeum of Uria aalge was of a different type, as the epithelium was multilayered, squamous and noncornified (Figs. 4a, b, c).

The morphology of the three main epithelial cell types, absorptive epithelial cells (AEC), mitochondria-rich cells (MR) and goblet cells (GC), observed in the Lagopus mutus, colon and coprodeum, and in the Uria aalge, colon, depicted very nicely the ion-transporting function as presented above (Figs. 1e, f, 2e, f, 3e, f). More specifically, the cells were provided apically with a brush border of densely packed microvilli, and the lateral cell membranes were sealed apically with tight junctions and elsewhere with cell-to-cell desmosomes. Intercellular interdigitations, which were sparse in the apical /luminal part of the membrane, increased and were converted into more complex patterns in the basal part of the cells. In both AEC and MR mitochondria, Golgi-complexes, lysosomes, vesicles, free 
ribosomes, RER and agranular ER, were present as observed in other ion transporting epithelial cells. The AEC and MR were very similar except for differences observed in the toluidin-blue affinity, electron density of the cytoplasm, the amount of mitochondria and the nuclear morphology. MR cells had a higher toluidin-blue affinity and electron density, more numerous mitochondria and a denser nucleus with deep indentations when compared to the AEC (Figs. 1e, f, 2e, f, 3e, f). The MR cell brush border was not found to protrude over the general epithelial surface as seen in other tissues (e.g. chicken coprodeum, Elbrønd et al. 1991, 1998, 1999, 2004). The morphology of the GC was typical for a unicellular glandular cell, with the nucleus positioned basally and the cytoplasm dominated by mucous granules (Fig. 1e). In the sparse cytoplasm the Golgi complex, together with RER and other cytoorganelles, filled up most of the space.

Specifically, the mucosa of the Lagopus mutus colon was composed of elongated leafshaped villi with crypt openings in between (Figs. 1a, b, d). Scanning electron microscopy (SEM) showed a large amount of mucus covering the luminal surface of the organ (Fig. 1a). The proportions of the 3 cell types was estimated by counting the cells on the sides of the villi and were found to be $63 \% \mathrm{AEC}, 17 \% \mathrm{GC}$ and $20 \% \mathrm{MR}$. The mucosa of the Lagopus mutus coprodeum was found to be dominated by irregular mucosal folds (rather than villi) and crypt openings in between (Fig. 2a, b, d). The cell proportions were slightly different and estimated to be $75 \%$ AEC, $12 \%$ GC and $13 \%$ MR.

There were no villi in the Uria aalge colon (Fig. 3) and so the mucosal surface was outlined with a high frequency of crypt openings (Figs. 3a, b, d). All three cell-types were identified in the epithelium (Figs. 3e, f). The estimated cell proportions were AEC, 67\%, GC, $28 \%$ and MR, 5\%. TEM showed that the terminal web was very clear and strong (Fig. 3f), and that the RER and ER were dilated and organised into several vesicle-like structures, also observed at the LM level (Fig. 3e, f). The cellular composition of the epithelium 
differed between the crypts and the intercryptal areas. In both regions AEC and GC were present, whereas MR were only observed in the intercryptal epithelium.

The mucosa of the Uria aalge coprodeum (Fig. 4) was very different from that of the colon and coprodeum of Lagopus mutus, as it was outlined with a multilayered, squamous, non-cornified epithelium (Figs. 4a, b, c). Thin "fingers" of propria protruded into the epithelium creating a folded pattern within the epithelium (Fig. 4b).

\section{Ion and substrate transport characteristics.}

\section{Lagopus mutus}

The initial values for short circuit current $\left(\mathrm{I}_{\mathrm{sc}}\right)$ and potential difference (PD) of Lagopus mutus colon showed a significant gradient along its length, increasing from proximal to distal colon and continuing to the coprodeum (Table 1, Fig. 5 insert). These initial values were zero in the proximal colon, and increased to around $+20 \mu \mathrm{A} / \mathrm{cm}^{2}$ in the distal colon and coprodeum, indicating cation (presumably sodium) absorption and/or anion secretion that is independent of nutrient cotransport. The addition of $20 \mathrm{mM}$ glucose to the mucosal side did not stimulate the $\mathrm{I}_{\mathrm{sc}}$ or PD significantly in any of the colonic segments or in coprodeum (Fig. 5), indicating an absence of sodium-glucose luminal transporters (SGLTs). There was a significant decrease in current in the middle colon segment, which remains unexplained. On the other hand, addition of phloridzin ( $100 \mu \mathrm{M}$ to both sides), which is considered a specific inhibitor of the SGLT in mammals (Toggenburger et al, 1982), significantly inhibited the $\mathrm{I}_{\mathrm{sc}}$ and PD in the coprodeum ( $\mathrm{p}<0.0001$ ), a segment generally thought to be devoid of any hexose transport (Skadhauge, 1981). There appeared to be a trend of increasing phloridzin effect from proximal colon to coprodeum, but the change in current was only significant in coprodeum. (Fig. 5). 
The presence of $\mathrm{Na}^{+}$-amino acid cotransporters was tested for by adding a mixture of leucine and lysine (4 mM each, both sides). This addition caused a significant stimulation in the proximal $(\mathrm{p}<0.02)$ and middle $(\mathrm{p}<0.05)$ parts of colon of $2-3 \mu \mathrm{A} / \mathrm{cm}^{2}$. A decreasing gradient was apparent towards the distal part with no significant stimulation in distal colon or coprodeum. In the coprodeum there was extensive hysteresis in the data, which produced a non-significant negative mean with a large deviation. Amiloride, which is a specific blocker of ENaCs, produced a significant decrease in both $\mathrm{I}_{\mathrm{sc}}$ and $\mathrm{PD}$ in all parts of colon and in coprodeum. The change in $\mathrm{I}_{\mathrm{sc}}$ was smallest in the proximal colon, at $-5 \mu \mathrm{A} / \mathrm{cm}^{2}$ (p $<$ $0.02)$, whereas middle $(\mathrm{p}<0.02)$ and distal $(\mathrm{p}<0.05)$ colon as well as coprodeum $(\mathrm{p}<$ 0.001), all showed declines of about $-15 \mu \mathrm{A} / \mathrm{cm}^{2}$ (Fig. 5). The final addition of theophylline (1.4 $\mathrm{mM}$ both sides), which is an inhibitor of phosphodiesterase and which has previously been shown to induce chloride secretion in the domestic fowl (Clauss et al. 1988; 1991), produced increases in the $I_{s c}$ in the distal colon $(p<0.02)$ and coprodeum $(p<0.02)$ of around $3 \mu \mathrm{A} / \mathrm{cm}^{2}$ (Fig. 5). The calculated transepithelial resistances (TER) were not significantly affected by these substances in any of the segments (Table 1).

\section{Uria aalge}

The initial $\mathrm{I}_{\mathrm{sc}}$ of the Uria aalge colon was negative as in the proximal part of the Lagopus mutus colon (Table 1, Fig. 6, insert). Glucose addition produced no significant change, while phloridzin caused a fair, but non-significant decrease in the $\mathrm{I}_{\mathrm{sc}}(\mathrm{p}=0.064)$. The amino acid mixture significantly stimulated the $\mathrm{I}_{\mathrm{sc}}$ (and PD) of the Uria aalge colon, causing a change in the positive direction by around $9 \mu \mathrm{A} / \mathrm{cm}^{2}$ and reversing the $\mathrm{I}_{\mathrm{sc}}$ from -5 to $+4.3 \mu \mathrm{A} / \mathrm{cm}^{2},(\mathrm{p}<0.05)$ (Figure 6$)$. Amiloride had no effects and there was no significant change caused by theophylline. The initial resistance was $95 \mathrm{ohm} \mathrm{cm}^{2}$ and was unaffected by

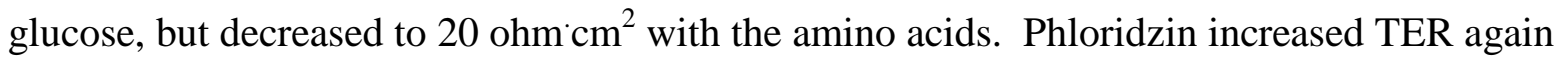


to about $100 \mathrm{ohm}^{\prime} \mathrm{cm}^{2}$ with no further change by either amiloride or theophylline. There were no effects caused by any of the substances in coprodeum, the $\mathrm{I}_{\mathrm{sc}}$ being very stable at about $+3 \mu \mathrm{A} / \mathrm{cm}^{2}$ (Fig. 6). The resistance was four-fold higher than in the coprodeum of Lagopus mutus, at $1000 \mathrm{ohm}^{\mathrm{cm}}{ }^{2}$ (Table 1). 


\section{Discussion}

The goals of this study were to compare the morphology and transport properties of the lower intestine of two wild bird species on naturally high and low salt diets, and further, to compare these properties with those of high and low salt-adapted chickens. In the domestic fowl, a low salt diet and the high circulating levels of aldosterone that result from it, suppress the activity of sodium-coupled hexose and amino acid transporters, and the protein expression levels of SGLT in the colon, while simultaneously increasing expression of amiloride-sensitive ENaC sodium channels in both the colon and coprodeum. Long-term acclimation to high salt completely reverses this transport pattern with cotransporter activity dominating in the colon and ion transport completely suppressed in the coprodeum (Árnason and Skadhauge, 1991; Chosniak et al, 1977; Clauss et al, 1988; 1991; Laverty et al, 2001; 2006). The current study was undertaken in part to test whether naturally high and low salt diets in different avian species are consistent with the different patterns resulting from artificial diets in domestic fowl.

Lagopus mutus. The mucosa of the Lagopus colon was developed into elongated leaf-shaped villi with crypt openings in between. The presence of villi-like structures in the colon has previously been reported in zebra finches (Poephila guttata), singing honeyeaters (Meliphaga virescens), senegal doves (Streptopelia senegalensis), emu (Dromaius novaehollandiae), rhea (Rhea americana) and adelie penguins (Pygoscelis adeliae) (Elbrønd et al, 2009; Johnson and Skadhauge, 1975; Olsen, et al, 2002; Skadhauge, 1981), as well as in the domestic fowl (Clauss et al, 1991; Laverty et al, 2001). However, the galah (Cacatua roseicapilla) and kookaburra (Dacelo gigas) have a much more mammalian-like morphology, dominated by crypt openings to a flat mucosal surface (Johnson and Skadhauge, 1975). Cell structure and ultrastructure of the Lagopus colon were also very similar to the domestic fowl colon (Elbrønd et al, 1998; 1999). The estimates of relative 
proportions of the three epithelial cell types (goblet cells (GC), 17\%, general absorptive epithelial cells (AEC), 63\% and mitochondria-rich cells (MR), 20\%) are generally similar to those of the domestic fowl coprodeum, the only tissue for which such measurements have been made (see below) (Elbrønd et al, 1998; 1999). The MR cells (formerly called brush cells) are of particular interest because of their postulated role in proton secretion and because of the marked increase in their cell number in hens adapted to low salt diets (Elbrønd et al, 1997; 1999).

Likewise the coprodeum of Lagopus was similar to that of the domestic fowl with mucosal folds, shorter than the colonic villi, and crypt openings between these folds. AEC, MR and GC are again represented in the coprodeum, with a similar MR proportion to that of low salt-adapted hen coprodeum. Elbrønd et al (1999) have reported an axial gradient of this cell type in the chicken, with the highest proportions (26\%) found in the proximal coprodeum and the lowest $(5 \%)$ in the most distal region. Also of interest is the fact that the chicken coprodeum undergoes a marked change in overall structure during adaptation to low salt diets. Thus, on high salt diets there are relatively short microvilli, low numbers of MR cells (5\% or less) and a lower total cell number. With low salt acclimation there is an increase in microvilli density and height, as well as increases in both total cell numbers and MR cell proportion (Elbrønd et al, 1991; 1998; 1999; Mayhew et al, 1992). This morphological adaptation to low salt has been clearly shown to correlate with changes in transport, with a large increase in sodium transport, mediated by $\mathrm{ENaC}$ channel upregulation (Elbrønd et al, 1991; 1999). Of interest is the finding of a similar difference in lower intestinal microvilli length and density between two races of savannah sparrows (Goldstein et al, 1990). Upland, migratory birds had extensive microvilli, comparable to the low salt adapted hen coprodeum, whereas a salt-marsh inhabiting race (with significantly higher 
plasma osmolalities) had sparse, poorly developed microvilli, as seen in the high salt coprodeum.

The electrophysiological analysis of Lagopus lower intestine also indicates a transport pattern similar to that of the low-salt adapted chicken (Árnason and Skadhauge, 1991; Chosniak et al, 1977; Clauss et al, 1988; 1991; Elbrønd et al, 1991; Lind et al, 1980; Laverty et al, 2001; 2006). Thus, the $\mathrm{I}_{\mathrm{sc}}$ is dominated by an amiloride-sensitive component, representing electrogenic sodium transport. This is particularly evident in the more distal regions of the colon and in the coprodeum. We found no significant glucose stimulated current in Lagopus colon, and there were no significant effects of phloridzin. This is again comparable to chickens that have been long-term adapted to a very low-salt diet or treated with aldosterone, where the colonic sodium-linked glucose cotransport is completely suppressed (Árnason and Skadhauge 1991; Laverty et al, 2001). This pattern of transport in Lagopus colon may be mediated by high levels of aldosterone, although no measurements were made in this study.

Phloridzin caused a significant reversed (negative) $\mathrm{I}_{\mathrm{SC}}$ in Lagopus coprodeum and a fairly large, but non-significant effect in distal colon. The inhibitory effect in coprodeum, which lacks glucose-stimulated $\mathrm{I}_{\mathrm{sc}}$, may indicate that it has non-specific effects in birds. Phloridzin is considered to be a specific inhibitor of sodium-glucose cotransport (Toggenburger et al, 1982), and is used extensively in studies on hexose transport in various epithelia to demonstrate the presence of Na-glucose cotransporters (Wright et al. 2004). The present results may indicate that phloridzin either has inhibitory actions on other transporters (Wright et al. 2004) or activates the equivalent of an anionic absorptive current.

There was significant amino acid stimulation in the proximal and middle colon segments in Lagopus mutus, but not in the distal colon or coprodeum. In domestic fowl that have been long-term adapted to very low-salt diets (Árnason and Skadhauge 1991), the 
colonic sodium-linked amino acid cotransport is completely suppressed in all parts of the colon and the transport pattern is altered to one that is mediated by electrogenic $\mathrm{ENaC}$ channels (Árnason and Skadhauge 1991; Laverty et al, 2001; 2006; Laverty and Skadhauge, 1999). Thus, the proximal region of the colon of Lagopus mutus, which lives on a natural low salt diet, differs from the low salt adapted hen. Glucose and amino acid cotransport may have multiple physiological roles in the lower intestine, increasing the recovery of these substrates from both intestinal and urinary sources, and at the same time providing an osmotic force for solute-linked water absorption (Árnason and Skadhauge 1991; Goldstein and Skadhauge, 2000; Laverty and Skadhauge, 1999; Skadhauge, 1981; Thomas, 1982). For example, urate spheres taken from the ureteral urine of hens contain large amounts of an albumin-like protein, which is thought to be degraded in the lower intestine and reabsorbed as amino acids or peptides (Braun, 2003). At the same time, the colons of hens and other species have been shown to be capable of driving net water absorption in vivo from luminal perfusion solutions, a process driven by these cotransporters (Bindslev and Skadhauge, 1971; Dawson et al, 1985; Goldstein and Braun, 1986; Goldstein et al, 1986; Skadhauge, 1974; Skadhauge et al, 1984). On high salt diets, elevated luminal osmolality (Skadhauge, 1968; Thomas 1982) could potentially lead to net loss of body water. Cotransporter activity with the potential for driving solute-linked water absorption (Wright et al, 2004) may help to offset this water loss.

Chloride secretory capacity was present in the Lagopus lower intestine, as demonstrated by significant effects of theophylline in the distal colon and coprodeum, as is the case with low-salt chickens (Arnason and Skadhauge 1991). Theophylline has previously been shown to be correlated with induction of chloride secretion in the hen (Clauss et al, 1988; 1991). 
Thus, for ptarmigan living on naturally low salt diets, lower intestinal transport is similar in most respects to the transport in low salt adapted chickens and appears to be adapted to maximizing sodium recovery from intestinal and refluxed urinary fluids via electrogenic, amiloride-inhibitable $\mathrm{ENaC}$ channels. This is especially true for the more distal segments, whereas the presence of sodium-amino acid cotransport in the more proximal segments may reflect the importance of amino acid conservation on a relatively protein poor diet. Braun (2003) also points out that the retrograde movement of urate and its subsequent breakdown may be critical as a source of nitrogen for the ptarmigan and other species on nitrogen-poor diets. These data also demonstrate clear axial variation in transport properties along the colon.

Uria aalge. The lower intestine of Uria was short, and the morphology distinctly different from that of Lagopus mutus. The mucosa of the colon lacks villi and the surface is dominated, instead, by numerous crypt openings. This structure generally resembles that of the mammalian colon (Lacy, 1991), and is also similar to the mucosal structure of two Australian bird species, the galah (Cacatua roseicapilla) and kookaburra (Dacelo gigas) (Johnson and Skadhauge, 1975). On the other hand, a recent study of the intestinal tract of Adelie penguins (Pygoscelis adeliae), another seabird, demonstrated villus-like structures in the colon (Olsen et al, 2002). In the Uria colon absorptive epithelial cells (AEC), with relatively short microvilli, comprised about $67 \%$ of the epithelium and goblet cells $28 \%$. Of particular interest is the low portion of MR cells in this tissue (estimated at 5\%), similar to the low frequency seen in the coprodeum of high salt-adapted hens (Elbrønd et al, 1999). The coprodeum of Uria, in contrast to the colon or coprodeum of chickens, was characterized by a multilayered, squamous epithelium, suggesting a non-transporting epithelium. 
The initial unstimulated transport activity in Uria aalge colon was minimal, but there was a significant stimulation of current with the addition of amino acids, and no amiloride-sensitive current. On the other hand, there was no significant effect of glucose addition and no significant phloridzin response. Overall, the Uria colon functions, at least in some respects, similarly to the high salt acclimated chicken colon, with sodium-linked cotransporter activity and little or no electrogenic sodium channel activity (Árnason and Skadhauge, 1991; Clauss et al, 1991; Lind et al, 1980, Laverty et al, 2001; 2006; Rice and Skadhauge, 1982). The multilayered, high resistance epithelium of the coprodeum exhibited no transport activity, consistent with an epithelium with low water permeability.

Our interpretation of these data is that the lower intestine (colon and coprodeum) of Uria aalge provides a mechanism to minimize water loss into a hypertonic lumen. The amino acid-stimulated current in the colon may represent a transport process that would allow for solute-linked water absorption against an osmotic gradient, at least to the extent of offsetting the osmotic flux into the lumen (Skadhauge, 1981; Thomas, 1982). The use of amino acid cotransporters rather than glucose cotransporters likely correlates with the high protein diets of these birds. Colonic solute-linked water transport from hyperosmotic luminal solutions has been demonstrated in vivo in chickens and house sparrows (Bindslev and Skadhauge, 1971; Goldstein and Braun, 1986), as well as in glaucous-winged gulls (Larus glaucescens), a seabird with a short lower intestinal segment like Uria (Goldstein et al, 1986 Interestingly, a study of mallard ducks found that chronic acclimation to saline increased the length of both the ceca and ileum, as well as ileal mass, particular in males (Hughes et al, 2002). Thus, colonic transport may represent only part of a much more elaborate system for conserving water in salt-stressed birds.

In summary, a comparison of lower intestinal morphology and transport activity in these two disparate species indicate marked differences related to both diet and salt intake. 
The results suggest that high salt intake is associated with a lower intestinal pattern of morphology and ion transport that maximizes water conservation by using low affinity cotransporters to drive solute-linked water transport against osmotic gradients, whereas low salt diets are associated with properties designed to maximize salt retention. These patterns are generally similar to those seen in high and low salt-acclimated domestic fowl, although the lack of hexose-stimulated cotransporter activity in Uria aalge and the presence of amino acid cotransporter activity in proximal regions of Lagopus mutus colon represent variations likely related to the marked differences in diet and natural history of these species. It should be noted that, while these data on wild birds are consistent with the changes in transport that occur with varying dietary salt intake in domestic fowl, it is also true that the species compared in this study come from two different avian orders. Furthermore, the previous work on lower intestinal function in domestic fowl are complicated by the long history of selective breeding in these strains. Thus, phylogenetic considerations and adaptive traits related to particular natural histories are also important in making comparisons of dietary salt effects. It will be important to the further understanding of the physiology of the avian lower intestine to study other species, including those from more closely-related taxa. 


\section{Acknowledgements}

The skilled help of Erlendur Jónsson, cand.scient., in the hunting of the ptarmigans in the lava-fields east of Reykjavík is greatfully acknowledged, as well as the skilled hunting by the rescue team of Björgunarsveitin Ingólfur of the murres in the cliffs of Krísuvíkurbjarg, south-west of Reykjavík. We also want to thank Henrik Simonsen and Hanne M Holm for their excellent technical assistance with the morphological preparations. This work was carried out on a Fulbright Research Grant to G. Laverty and was made possible with the support of the Iceland-United States Education Commission, the Icelandic Research Council and the University of Iceland Research Fund (S.S. Árnason). Additional support was from National Science Foundation Grant IBN-9870810 (G. Laverty) and from the Danish Agricultural and Veterinary Research Council (V.S. Elbrønd). Permissions to catch the wild birds at these locations and time of year for research were obtained from the Icelandic National Committee of Wild Life (98010080/13-4-1). These experiments comply with the laws of animal protection and research of Iceland. 


\section{References}

Árnason SS, Skadhauge E (1991) Steady-state sodium absorption and chloride secretion of colon and coprodeum, and plasma levels of osmoregulatory hormones in hens in relation to sodium intake. J Comp Physiol B 161:1-14

Bindslev N, Skadhauge E (1971) Sodium chloride absorption and solute-linked water flow across the epithelium of the coprodeum and large intestine in the normal and dehydrated fowl (Gallus domesticus). In vivo perfusion studies. J Physiol 216:753-768

Bindslev N, Hirayama BA, Wright EM (1997) Na/D-glucose cotransport and SGLT1 expression in hen colon correlates with dietary $\mathrm{Na}^{+}$. Comp Biochem Physiol A 118:219227

Bradstreet MSW, Brown RGB (1985) Feeding ecology of the Atlantic Alcidae. In: Nettleship DN, Birkhead TR (eds)The Atlantic Alcidae. Academic Press, New York, pp263-318

Braun EJ (2003) Regulation of renal and lower gastrointestinal function: role in fluid and electrolyte balance. Comp Biochem Physiol A 136:499-505

Choshniak I, Munck BG, Skadhauge E (1977) Sodium chloride transport across the chicken coprodeum. Basic characteristics and dependence on sodium chloride intake. J Physiol 271:489-503

Clauss W, Dantzer V, Skadhauge E (1988) A low -salt diet facilitates Cl secretion in hen lower intestine . J Membrane Biol 102:83-96

Clauss W, Dantzer V, Skadhauge E (1991) Aldosterone modulates electrogenic Cl secretion in the colon of the hen (Gallus domesticus). Am J Physiol 261:R1533-R1541 
Dawson TJ, Herd RM, Skadhauge E (1985) Osmotic and ionic regulation during dehydration in a large bird, the emu (Dromaius novaehollandiae): an important role for the cloaca-rectum. Quart J Exp Physiol 70:423-436

Elbrønd VS, Dantzer V, Mayhew TM, Skadhauge E (1991) Avian lower intestine adapts to dietary salt $(\mathrm{NaCl})$ depletion by increasing transepithelial sodium transport and microvillous membrane surface area. Exp Physiol 76:733-744

Elbrønd VS, Skadhauge E, Thomsen L, Dantzer V (1998) Morphological adaptations to induced changes in transepithelial sodium transport in chicken lower intestine (coprodeum): a study of resalination, aldosterone stimulation, and epithelial turnover. Cell Tissue Res 292:543-552

Elbrønd VS, Dantzer V, Skadhauge E (1999) Differences in epithelial morphology correlate to $\mathrm{Na}^{+}$-transport: A study of the proximal, mid, and distal regions of the coprodeum from hens on high and low $\mathrm{NaCl}$ diet. J Morphol 239:75-86

Elbrønd VS, Jones CJP, Skadhauge E (2004) Localization, morphology and function of the mitochondrial-rich cells in relation to transepithelial $\mathrm{Na}^{+}$-transport in chicken lower intestine (coprodeum). Comp Biochem Physiol A 137:683-696

Elbrønd VS, Laverty G, Dantzer V, Grøndahl C, Skadhauge E (2009) Ultrastructure and electrolyte transport of the epithelium of coprodeum, colon and the proctodeal diverticulum of Rhea americana. Comp Biochem Physiol A 152:357-365

Gasaway WC (1976) Cellulose digestion and metabolism by captive rock ptarmigan. Comp Biochem Physiol A 54:179-182

Gaston AJ, Jones IL (1998) Common murre. In: The Auks (Alcidae). Oxford University Press, Oxford, pp 133-147

Goldstein DL, Braun EJ (1986) Lower intestinal modification of ureteral urine in hydrated house sparrows. Am J Physiol 250: R89-R95 
Goldstein DL, Hughes MR, Braun EJ (1986) Role of the lower intestine in the adaptation of gulls (Larus glaucescens) to seawater. J Exp Biol 123:345-357

Goldstein DL, Williams JB, Braun EJ (1990) Osmoregulation in the field by salt-marsh savannah sparrows Passerculus sandwichensis beldingi. Physiol Zool 63:669-682

Goldstein DL (1993) Influence of dietary sodium and other factors on plasma aldosterone concentrations and in vitro properties of the lower intestine in house sparrows (Passer domesticus). J Exp Biol 176:159-174

Goldstein DL, Skadhauge E (2000) Renal and extrarenal regulation of body fluid composition. In: Whittow GC (ed) Avian Physiology, Fifth Ed, Academic Press, New York, pp 265-297

Holmes WN, Phillips JG (1985) The avian salt gland. Biol Rev 60:213-256

Hughes MR, Bennett DC, Sullivan TM (2002) Effect of saline drinking water on the size and water content of the gut and other organs of male and female mallards. Can J Zool $80: 70-76$

Johnsgard PA (1983) Rock ptarmigan. In: The Grouse of the World. University of Nebraska Press, Lincoln, pp 189-205

Johnson OW, Skadhauge E (1975) Structural-functional correlations in the kidneys and observations of colon and cloacal morphology in certain Australian birds. J Anat $120: 495-505$

Lacy ER (1991) Functional morphology of the large intestine. In: Schultz SG (ed) Handbook of Physiology, Sect 6, The Gastrointestinal Tract. Vol IV, Intestinal Absorption and Secretion. American Physiological Society, Bethesda, pp121-194 Laverty G (1997) Transport characteristics of the colonic epithelium of the Japanese quail (coturnix coturnix). Comp Biochem Physiol A 118:261-263 
Laverty G, Skadhauge E (1999) Physiological roles and regulation of transport activities in the avian lower intestine. J Exp Zool 283: 480-494

Laverty G, Bjarnadóttir S, Elbrønd VS, Árnason SS (2001) Aldosterone suppresses expression of an avian colonic sodium-glucose cotransporter. Am J Physiol 281:R1041R1050

Laverty G, Elbrønd VS, Árnason SS, Skadhauge E (2006) Endocrine regulation of ion transport in the avian lower intestine. Gen Comp Endocrinol 147:70-77

Lilliendahl K, Solmundsson J (1997) An estimate of summer food consuption of six seabird species in Iceland. ICES J Marine Sci 54:624-630

Lind J, Munck BG, Olsen O, Skadhauge E (1980) Effects of sugars, amino acids and inhibitors on electrolyte transport across hen colon at different sodium chloride intakes. J Physiol 305:315-325

Mayhew TM, Elbrønd VS, Dantzer V, Skadhauge E (1992) Quantitative analysis of factors contributing to expansion of microvillous surface area in the coprodaeum of hens transferred to a low $\mathrm{NaCl}$ diet. J Anat 181:73-77

Moss R (1989) Gut size and the digestion of fibrous diets by tetraonid birds. J Exp Zool Suppl 3:61-65

Olsen MA, Myklebust R, Kaino T, Elbrønd VS, Mathiesen SD (2002) The gastrointestinal tract of Adélie penguins-morphology and function. Polar Biol 25:641-649

Rice GE, Skadhauge E (1982) Colonic and coprodeal transepithelial transport parameters in NaCl-loaded domestic fowl. J Comp Physiol B 147: 65-69

Schmidt-Nielsen K, Borut A, Lee P, Crawford E Jr (1963) Nasal salt excretion and the possible function of the cloaca in water conservation. Science 142:1300-1301

Schmidt-Nielsen K (1997) Physiology. Adaptation and Environment. Fifth Ed, Cambridge University Press, Cambridge 
Skadhauge E (1974) Cloacal resorption of salt and water in the galah (Cacatua roseicapilla). J Physiol 240:763-773

Skadhauge E, Dawson TJ (1980) In vitro studies of sodium transport across the lower intestine of a desert parrot. Am J Physiol 239:R285-R290

Skadhauge E (1981) Osmoregulation in Birds. Springer-Verlag, Berlin

Skadhauge E, Munck BG, Rice GE (1984) Regulation of $\mathrm{NaCl}$ and water absorption in duck intestine. In: Pequeux A,Gilles R, Bolis L (eds) Osmoregulation in Estuarine and Marine Animals. Springer-Verlag, Berlin, pp131-142

Takata K, Kasahara T, Kasahara M, Ezaki O, Hirano H (1991) Localization of $\mathrm{Na}^{+}-$ dependent active type and erythrocyte/hepG2-type glucose transporters in rat kidney: immunofluorescence and immunogold study. J Histochem Cytochem 39:287-298

Thomas (1982) Salt and water excretion in birds: the lower intestine as an integrator of renal and intestinal excretion. Comp Biochem Physiol A 71:527-535

Toggenburger G, Kessler M, Semenza G (1982) Phlorizin as a probe of the small-intestinal $\mathrm{Na}^{+}$, D-glucose cotransporter. A model. Biochim Biophys Acta 688:557-571

Wright EM, Loo DDF, Hirayama BA and Turk E (2004) Surprising versatility of $\mathrm{Na}^{+}-$ glucose cotransporters: SLC5 Physiology 19:370-376 


\section{Figure Legends}

Figure 1. Morphology of the Lagopus mutus colon. 1a: SEM showing the mucosal surface with villi (arrowheads) and crypt openings covered by mucous. 1b: SEM image showing top of one villus. 1c: Higher magnification SEM of the top, showing the apical surface amplified with microvilli. 1d: LM of the villi (arrowhead) and crypts (arrow), 1e: Higher magnification LM (toluidin blue staining) showing the three epithelial cell types: absorptive intestinal epithelial cells (AEC), goblet cells (GC) and mitochondria-rich cells (MR). 1f: TEM confirming the presence of the three cell-types (seen in1e).

Figure 2. Morphology of the Lagopus mutus coprodeum. 2a: SEM of the mucosal surface showing the mucosal folds (arrowhead) and crypt openings (arrows) in between. 2b: An isolated fold showing the irregular top (arrowhead) of a fold and crypt openings in between (arrow). 2c: Higher magnification SEM showing the apical surface of the mucosal top, amplified with microvilli. AEC and GC are seen in this image. 2d: LM of the mucosal folds with the irregular tops and crypt openings in between. 2e: Higher magnification LM showing the different cell-types, AEC, GC and MR (toluidin blue staining). 2f: TEM showing AEC and GC at the ultrastructural level.

Figure 3. Morphology of the Uria aalge colon. 3a: SEM of the mucosal surface showing crypt openings (arrows). 3b: Crypt opening (arrow) and the surrounding surface epithelium. 3c: Higher magnification SEM of the edge of a crypt opening showing apical cellular amplification of AEC with microvilli and the presence of goblet cells (GC). 3d: LM showing the mucosa with the crypt openings (arrows) and the epithelial cells outlining the mucosal surface. 3e: Higher magnification LM of the epithelium showing the three cell types: AEC, MR and GC (toluidin blue staining). 3f: TEM of the epithelium showing morphological details of the three cell types. An apical terminal web is seen in the epithelial cells as an electron dense filamentous meshwork.

Figure 4. Morphology of the Uria aalge coprodeum. 4a: SEM showing the mucosal surface of the squamous multilayered non-cornified epithelium. 4b: LM showing 
the epithelium and the thin spines of the propria (arrows) inserted into the epithelium. 4c: Higher magnification LM showing the multilayered structure of the epithelium.

Figure 5. Changes in Lagopus mutus colonic and coprodeal $I_{s c}$. Delta $I_{s c}$ values are plotted for the proximal (PC), mid (MC) and distal (DC) colon, as well as for coprodeum (COP), in response to addition of various substances. After an initial $60 \mathrm{~min}$ stabilization period, the following additions were made: $20 \mathrm{mM}$ glucose added to the mucosal side reservoir; $4 \mathrm{mM}$ each of leucine and lysine added to both sides; $100 \mu \mathrm{M}$ phloridzin, both sides; $100 \mu \mathrm{M}$ amiloride, mucosal side; and $1.4 \mathrm{mM}$ theophylline, both sides. Twenty to thirty min stabilization periods were allowed between each addition. Insert: Initial $\mathrm{I}_{\mathrm{sc}}$ values in each of the four tissue segments after the $60 \mathrm{~min}$ stabilization period and prior to mucosal glucose addition. Negative values reflect a decrease in $I_{s c}$ from previous value. All values are means \pm SEM. Symbols indicate values significantly different from zero: $\star, p<0.05$; $\star \star, \mathrm{p}<0.02 ; \star \star \star, \mathrm{p}<0.001$. Letters indicate initial $\mathrm{I}_{\mathrm{sc}}$ values significantly different from each other $(\mathrm{p}<0.05)$.

Figure 6. Changes in Uria aalge colonic and coprodeal $I_{s c}$. Delta $I_{s c}$ values are plotted for Uria aalge colon (COL) and coprodeum (COP) in response to addition of various substances. After an initial 60 min stabilization period, the following additions were made: $20 \mathrm{mM}$ glucose added to the mucosal side reservoir; $4 \mathrm{mM}$ each of leucine and lysine added to both sides; $100 \mu \mathrm{M}$ phloridzin, both sides; $100 \mu \mathrm{M}$ amiloride, mucosal side; and $1.4 \mathrm{mM}$ theophylline, both sides. Twenty to thirty min stabilization periods were allowed between each addition. Insert: Initial $I_{\mathrm{sc}}$ values in colon and coprodeum after the $60 \mathrm{~min}$ stabilization period and prior to mucosal glucose addition. Negative values reflect a decrease in $\mathrm{I}_{\mathrm{sc}}$ from previous value. All values are means \pm SEM. $\star$, value significantly different from zero, $\mathrm{p}<$ 0.05 . 


\section{Tables}

Table $1 \mathrm{I}_{\mathrm{sc}}, \mathrm{PD}$ and $\mathrm{R}$ in colon and coprodeum of Lagopus mutus and Uria aalge

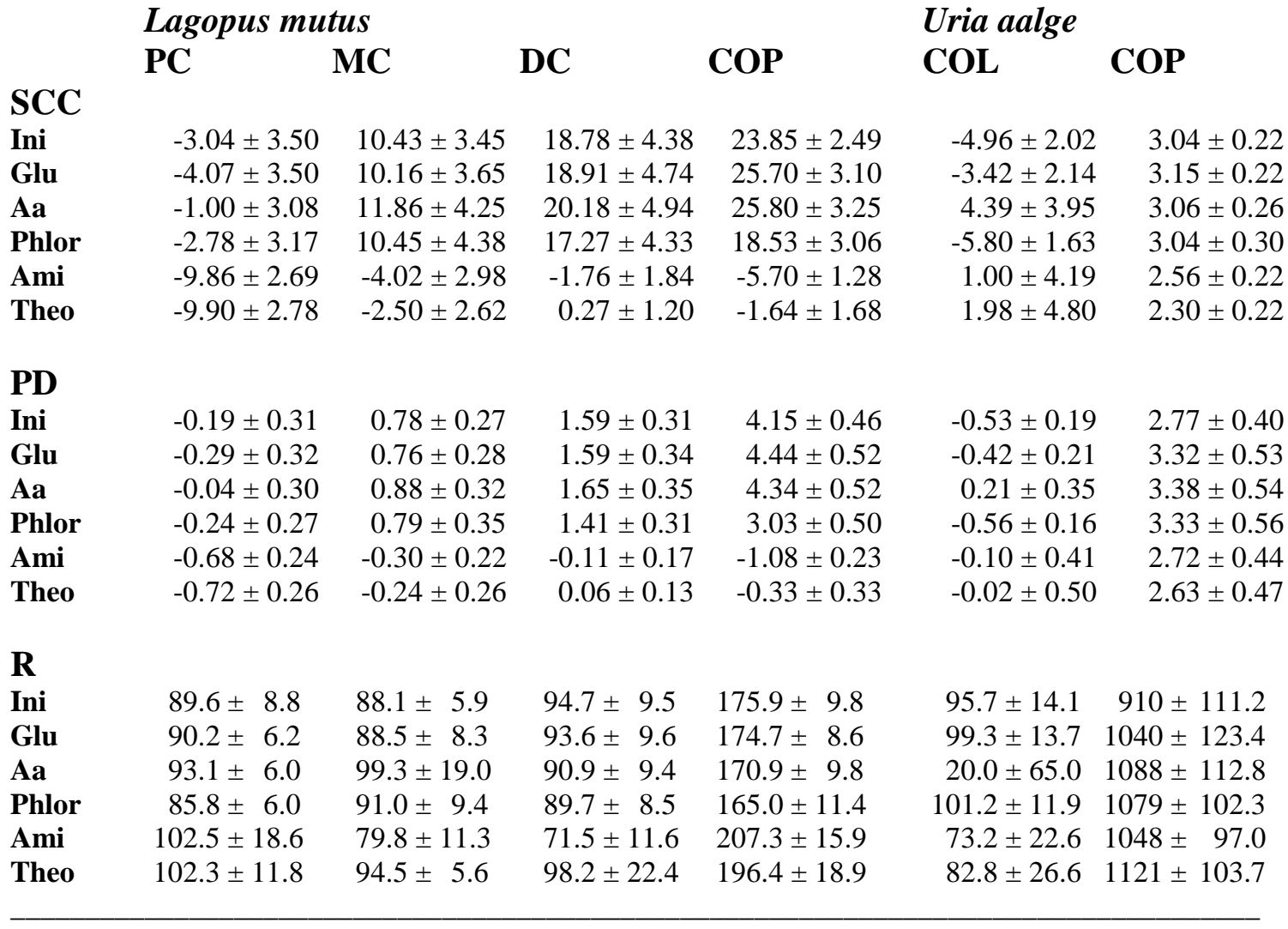

Results are means \pm SEM, $n=9$ for Lagopus mutus and $n=5$ for Uria aalge. Ini $=$ stabilized values before glucose addition. Other means are stabilized posttreatment values 15-20 min after addition of each substance (see Materials and Methods). Substances were added in the following order: $20 \mathrm{mM}$ glucose (Glu), mucosal side; a mixture of $4 \mathrm{mM}$ leucine and lysine (Aa), both sides; $100 \mu \mathrm{M}$ phloridzin (Phlor), both sides; $100 \mu \mathrm{M}$ amiloride (Ami), mucosal side; $1.4 \mathrm{mM}$ theophylline (Theo), both sides. PC, MC and DC: proximal, mid and distal colon tissues from Lagopus mutus. COL, Uria aalge colon; COP, coprodeum. 

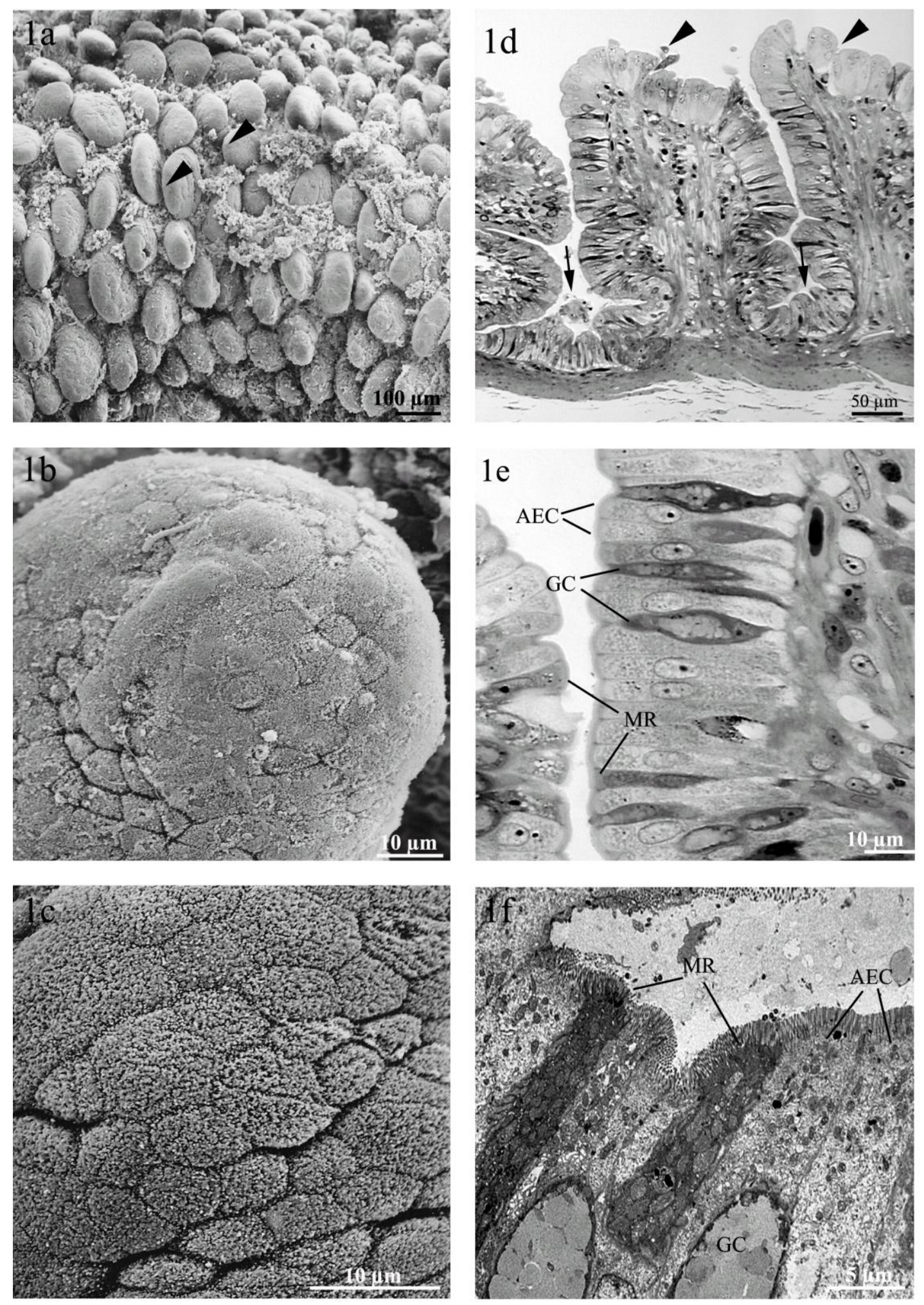

Fig. 1 

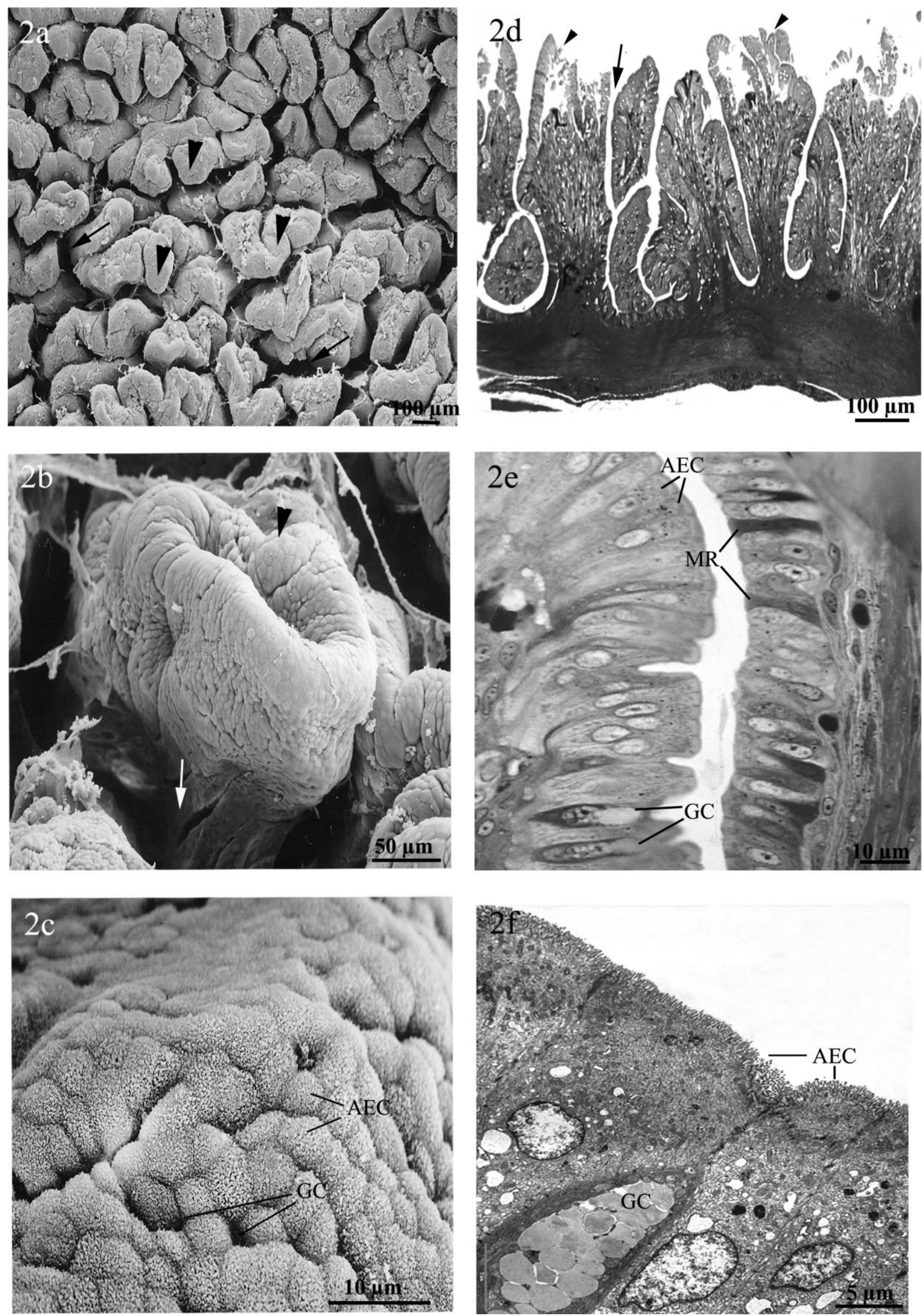

Fig. 2 

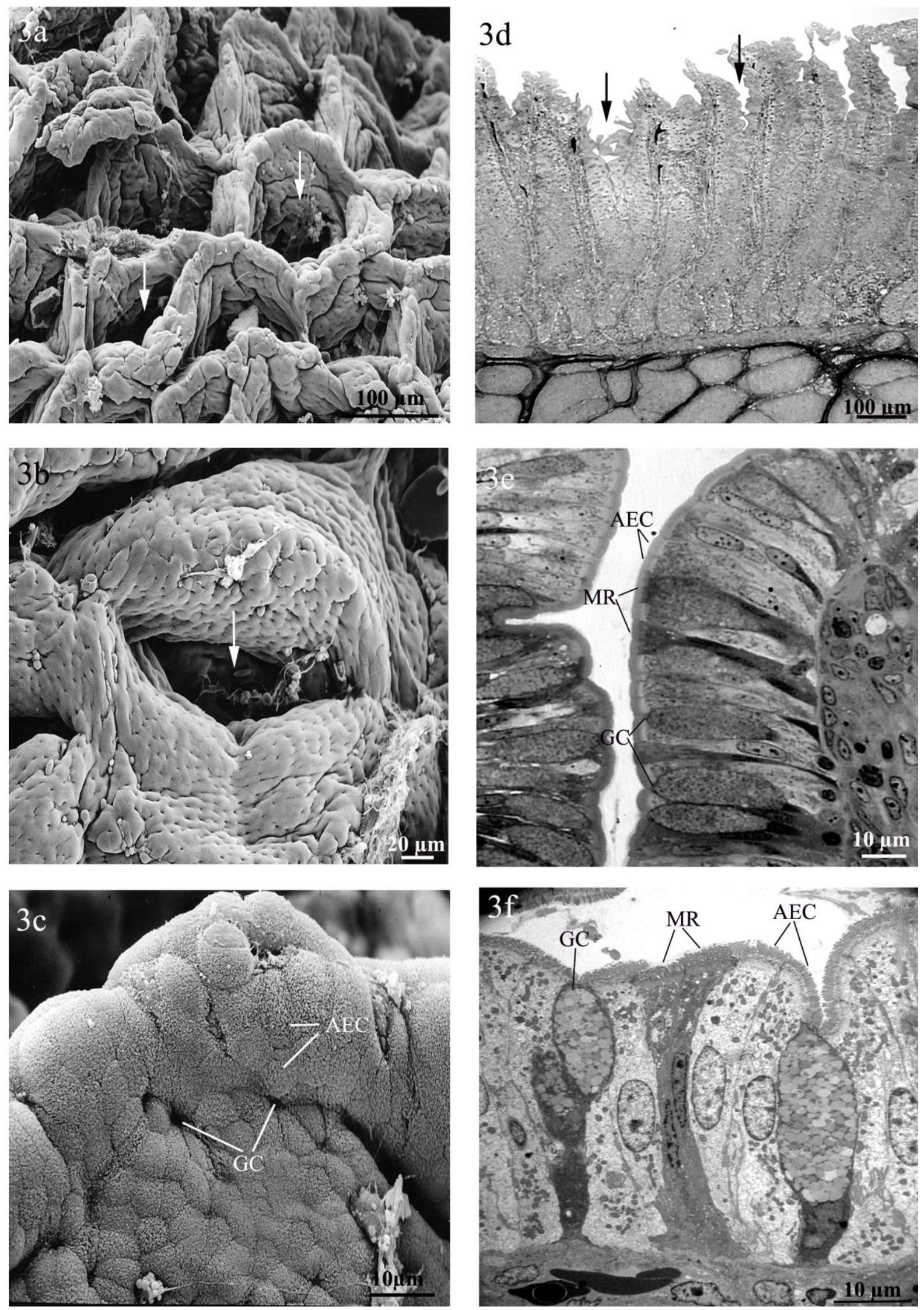

Fig. 3 


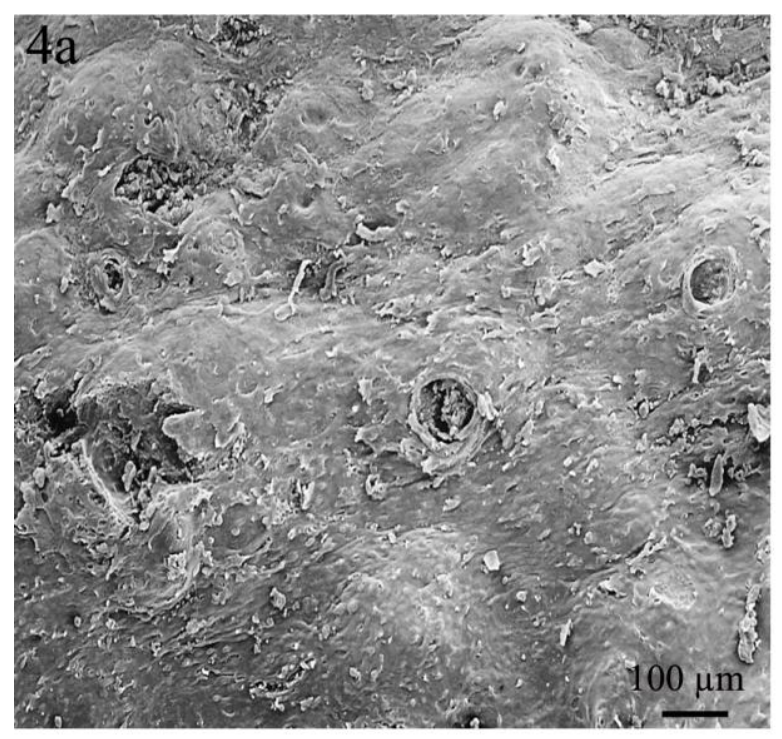

$4 b$

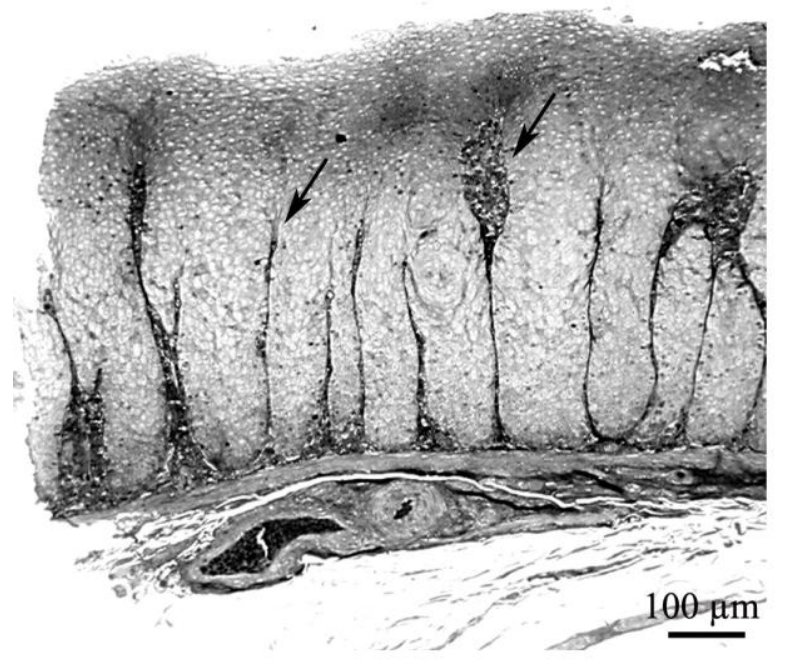

$4 c$

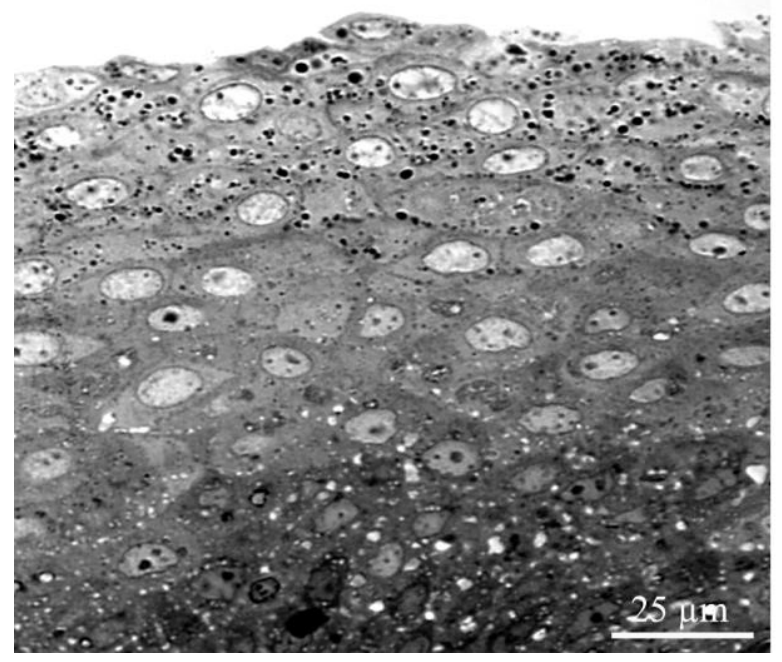

Fig. 4 


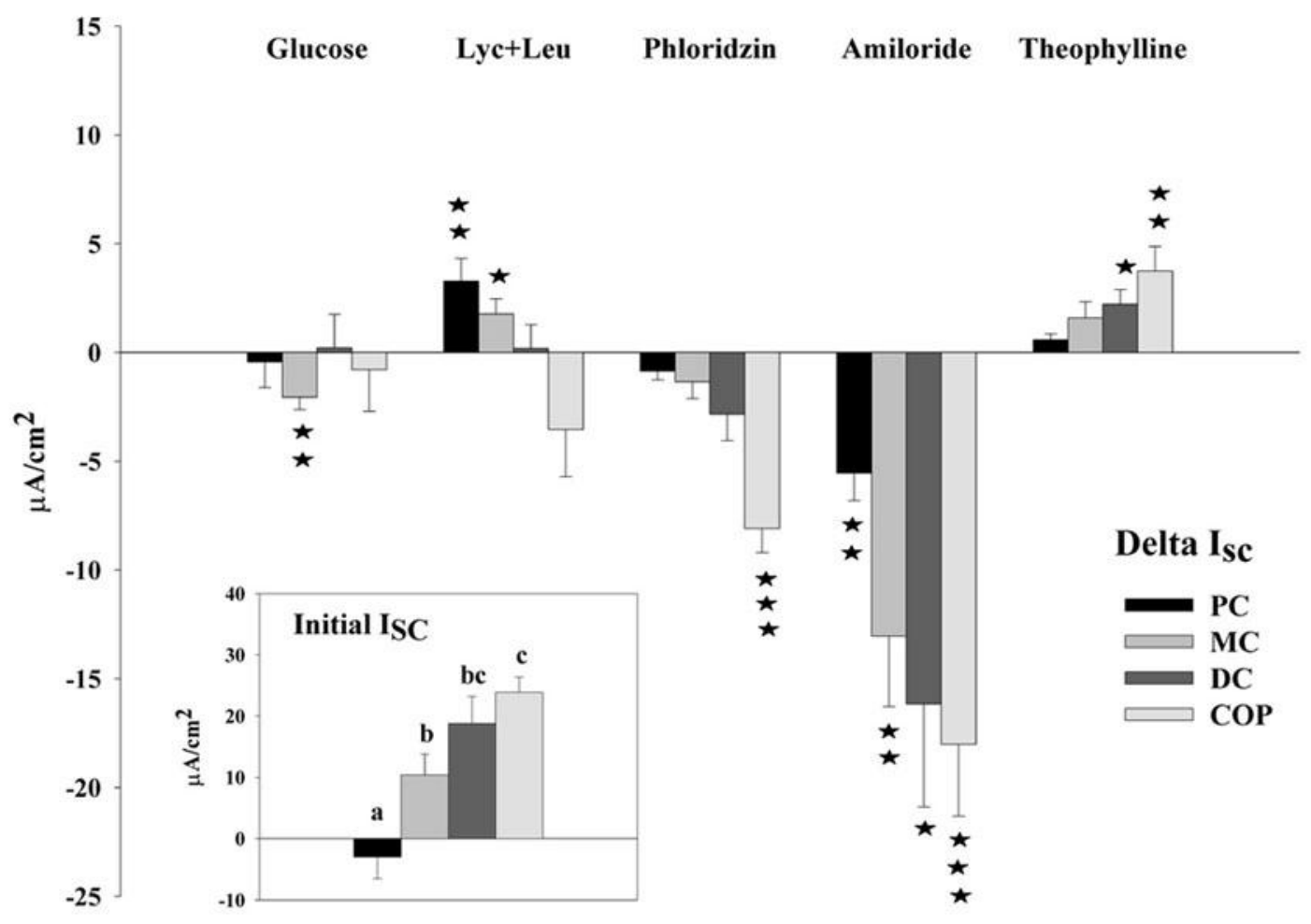

Fig. 5 


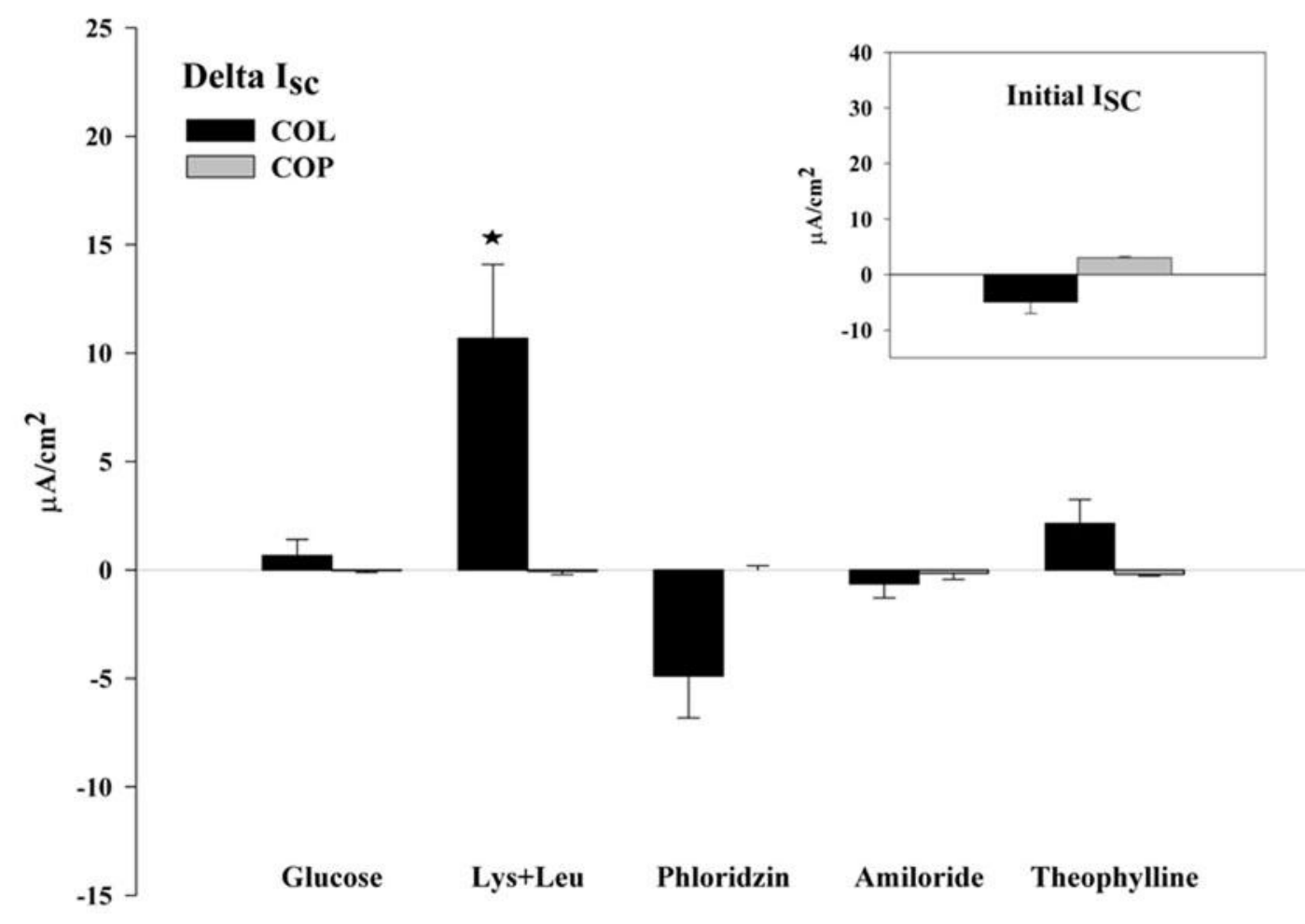

Fig. 6 